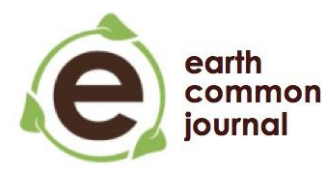

Earth Common Journal

Convergence

MacEwan University

Volume 5, Number 1, September 2015

\title{
Article
}

\section{Impacts and Assessment of the Endangered Snow Leopard: A conservational approach}

Averil Jones

MacEwan University, Canada

\begin{abstract}
Overcoming the threats of the snow leopard with immediate action may be what will save this species from extinction. This report provides a brief overview both of the challenges faced by the snow leopard and the roles local people have taken in the decline and subsequent recovery of this apex predator. Panthera uncia lives across the high-alpine regions of Central Asia, with China containing most of their habitat. It is estimated that only $550,000 \mathrm{~km}^{2}$ of this territory is good quality habitat. These predators will adjust their territory size and range in accordance with their ungulate prey. Under the Conservation Monitoring Centre of the International Union for Conservation of Nature (IUCN), they have been listed as endangered since 1996. Since 1975, all international trade has been prohibited after being listed with the Convention on International Trade in Endangered Species of Fauna and Flora (CITES). The International Snow Leopard Trust and the Snow Leopard Survival Strategy are promoting conservation through scientifically based research. Numerous threats have been identified: decline in prey populations, habitat degradation, trophy and black market hunting, ineffective law enforcement, a lack of
\end{abstract}


knowledge about conservation efforts, and climate change. It is estimated that $30 \%$ of their habitat will be subject to change along the Himalayas. The Snow Leopard Survival Strategy is promoting livestock and grazing practices that will reduce vulnerability to predation, such as the use of herding dogs to ward off predators. An underlying problem that ties the numerous issues together is the poverty in most of the countries that are part of snow leopard range, and this draws a link between biodiversity conservation and the well-being of those people. Regional conservation programs depend not only on the effective enforcement of protection laws, but also on the proof that wildlife conservation can provide new opportunities to the local people who are impacted by this species. To save this species, these areas need to be conserved and managed, and the rural communities need to be educated and supported.

\section{Introduction}

Our planet and wildlife are being subjected to increasing stress. As human population and production increase, so does the threat of extinction to many species. To counter this process, we need to increase awareness and education about this threat. In the mountains of Central Asia, a precious creature struggles for survival. Shedding light on the difficulties of this secretive and beautiful cat will lead to conservation action and the road to recovery can begin. Recognizing the threats to the snow leopard, paired with actions to meet those threats, can help save this species from extinction. This report provides a summary of the challenges this species and the local people of Central Asia face and of the actions that need to be taken.

\section{Life History and Species Status}

Secretive and well-camouflaged, this large cat is the least known of all felids, (a member of the biological family of cats, Felidae) (McCarthy, Fuller, \& Munkhtsog 2005, p. 527). The first photograph of this creature was not published until 1980 (McCarthy, K.P., Fuller, Ming, McCarthy, T.M., Waits, \& Jumabaev, 2008, p. 1826). The snow leopard is a member of the family Felidae, subfamily Pantherinae, and is sometimes placed in a separate genus, Uncia, based on its morphology and behaviour. However, most authors refer to them as Panthera uncia (McCarthy \& Chapron, 2003, p. 9).

Snow leopards are well-adapted to life at high altitudes (900-4000 m) and cold temperatures, with a coat colour of dark grey rosettes and spots that fades into white on the underbelly, an enlarged nasal cavity, shortened limbs, well-developed chest muscles, 
and a tail up to $1 \mathrm{~m}$ long. They are superbly camouflaged in the rock and snow-covered alpine terrain (McCarthy \& Chapron, 2003, p. 13).

As with most mammalian species, the male, at $45-55 \mathrm{~kg}$, is slightly larger than the female, at 35-40 kg (McCarthy \& Chapron, 2003, p. 13). Snow leopards are often solitary, with mating occurring between late January and mid-March. The gestation period is 93110 days; births, generally in June or July, produce one to five cubs. Reproduction rates are low for snow leopards, as few offspring survive to reproductive age (para. 3).

Their preferred habitat is alpine and sub-alpine containing arid and semi-arid shrub land that is cold, bushy, and rocky (Lovari, Ventimiglia, \& Minder, 2013, p. 308). Additionally, they can be found in coniferous forest or flat to rolling terrain, provided there is enough cover (Jackson, Mallon, McCarthy, Chundaway \& Habib 2014, para. 9). Harsh climate conditions and low resource availability characterize this style of ecosystem (Lovari et al., 2013, p. 315). Their range spreads across the mountains of Central Asia: Altai, Tian Shan, Kun Lun, Pamir, Hindu Kush, Karakorum, and the Himalayan mountains (Jackson et al., 2008, para. 9). Much is unknown about the species' home range, but it is estimated at more than three million $\mathrm{km}^{2}$, with only approximately $550,000 \mathrm{~km}^{2}$ of good quality habitat (para. 6). These areas include territory within their native countries: Afghanistan, Bhutan, China (more specifically, the Gansu, Qinghai, Sichuan, Tibet, Xinjiang, and Yunnan provinces), India, Kazakhstan, Kyrgyzstan, Mongolia, Nepal, Pakistan, Russia, Tajikistan, and Uzbekistan (para. 8). China alone contains an estimated $60 \%$ of their habitat (McCarthy \& Chapron, 2003, p. 9).

Their preferred hunting ground is open terrain broken by cliffs, ridges, and gullies. These opportunistic hunters will adjust their home range in response to changes in prey density, more specifically to areas with high ungulate (hoofed mammals) densities (McCarthy et al., 2008, p. 1828). In the Himalayas, their main prey consists of ungulates: blue sheep or bharal (Psendois nayaur); Himalayan tahr (Hemitragus jemlahicus), related to the wild goat; argali or mountain sheep (Ovis ammon); goral (Naemorhedus goral), goat-like in appearance; and musk deer (moschus sp.). On other mountain ranges, they prey on wild goats such as the Siberian ibex (Capra sibirica), markhor (Capra falconeri), and wild sheep such as urials (Ovis vignei) (Lovari et al., 2013, p. 308). They also utilize smaller prey including marmots (Marmota sp.), pika (Ochotona sp.), hares (Lepus sp.), small rodents and game birds (Jackson et al., 2008, para. 11). 


\section{Threats and Impacts}

Despite their extensive geographic range, snow leopards have low, fragmented densities, with a global population estimated at only 4,080-6,590 individuals (Jackson et al., 2008, para. 3). These numbers represent mature adults capable of reproduction. China has the largest estimated population, 2,000-2,500 individuals, followed by Mongolia with 500-1,000 individuals (para. 9). The Conservation Monitoring Centre of the International Union for Conservation of Nature (IUCN) has listed the snow leopard as endangered since 1986 (para. 4). Their population has declined by 20\% in the past 16 years (para. 2) and is expected to continue to decline by $50 \%$ or more over the next three generations (McCarthy \& Chapron, 2003, p. 9). The Convention on International Trade in Endangered Species of Fauna and Flora (CITES) has included them since 1975 in Appendix I, thus prohibiting international trade (p. 24). By implementing long-term conservation plans and involving the local affected communities, the International Snow Leopard Trust (1981) focuses on the protection of snow leopards and their habitat (Snow Leopard Trust, 2015). Similarly, the Snow Leopard Survival Strategy (SLSS), founded in 2002, aspires to promote sound, scientifically-based conservation and provide research and conservation strategies through collaboration with numerous organizations, scientists, and governments (McCarthy \& Chapron, 2003, p. 12). These organizations (IUCN, CITES, International Snow Leopard Trust, and SLSS) all have common goals, including assessing and prioritizing threats, promoting conservation, increasing education, developing policies and viable research methods, and building a network of scientists and conservationists (p. 12). In 2008, there was a conservation planning conference in Beijing to determine the most important areas for conservation and to identify where information is lacking (Jackson et al., 2008, para. 22).

\section{Habitat and Natural Prey}

Inside and near protected areas, the threat to snow leopards from habitat degradation and fragmentation is increasing due to livestock grazing, forest clearing for agriculture and pasture, and the collection of medicinal and aromatic plants (Forrest, Wikramanayake, Shrestha, Areendran, Gyeltshen, Maheshwari, Mazumdar, Naidoo, Thapa, K., Thapa, G.J., 2010, p. 133). Ungulates, their natural prey, have increasing competition for resources from high-altitude, domestic livestock. As habitat carrying capacity declines and numbers of livestock increase, snow leopard populations are directly and negatively impacted (McCarthy \& Chapron, 2003, p. 30). A study by McCarthy and Fuller (2005) on movements and activities of snow leopards in southwestern Mongolia found there was a prey to predator ratio of 114-230:1 (ibex: snow leopard) (p. 1826-1853). This ratio shows 
that snow leopards require large ungulate populations. These populations, however, are also decreasing from many factors: disease, impeded dispersal, migration, unregulated hunting for meat and trophies, and breeding aggregation caused by fencing around areas such as the borders of former Soviet Bloc countries. (McCarthy \& Chapron, 2003, p. 30).

\section{Direct Killing and Trapping}

A study done by Bhatnagar, Mathur, and McCarthy (2002) in India's trans-Himalayan region found that 14 animals a year were lost to snow leopard predation (p. 33). This predation is a result of the Tragedy of the Commons, which Pires and Moret (2011) explain, "occurs when individuals working independently of one another will overuse a common-property resource for short-term benefits while decimating the resource for long-term use" (p. 101). For snow leopards, the Tragedy of the Commons can be seen in their over-exploitation, their natural prey, and a decrease in their habitat. In response, snow leopards have switched to preying on domestic livestock-up to $58 \%$ of their diet in some places (Jackson et al., 2008, para. 19).

Loss of the livestock is a direct loss to herders in Central Asia: livestock are an important part of the local economy. In India's Kibber Wildlife Sanctuary, 18\% of livestock were killed by snow leopards and wolves (Canis lupus), with an estimated annual loss of income of $\$ 120$ US dollars; a significant loss considering the approximate annual income is $\$ 200-\$ 400$ (Jackson \& Wangchuk, 2001, p. 138). Another study on the Tibetan plateau found that on average $2 \%-9.5 \%$ of livestock were killed by snow leopards. This percentage increased during the winter, as climate conditions became harsher and their small prey, such as marmots, went into hibernation (McCarthy \& Chapron, 2003, p. 13). Because of this predation and its consequences, a negative attitude is created, and snow leopards are killed or removed in retribution by the herders who, coincidentally, have inadequate livestock guarding practices. Trade in snow leopard hide and bones can provide a herder with a few hundred dollars or more on the international black market (p. 30). Thus, local populations may see the snow leopard as a source of income, reflecting the underlying problem of poverty (p. 40). According to Wen (2002), in October 2001, police in Akesu, a city in the Xinjiang region of China, arrested a herdsman in Tahelahe for trapping and killing a snow leopard inside Tuomur Mt. Nature Reserve (p. 2). This shows both the lack of awareness among herdsmen for conservation and protection laws and their troubled economic status.

Additionally, the snow leopard is poached solely for the hide, bones, claws, and meat. Traditional Chinese medicine uses the meat and bones; the bones are a substitute for tiger bone, which was originally used (Jackson et al., 2008, para. 20). Chinese medicine 
manufacturers receive them through legal or illegal means. According to the Xinjiang Institute of Biology and Geography, 20-30 snow leopards are poached per year in the Xinjiang Urgur Autonomous region (Wen, 2002, p. 2). Snow leopard meat is also served as an exotic dish in the province of Sichuan (p. 3).

Zoos and circuses want to include snow leopards, particularly cubs, to attract more visitors (Wen, 2002, p. 1). To this end, zoos get involved in international animal exchanges. For instance, on September 17, 1997, three snow leopards were exchanged by the Rotterdam Zoo in the Netherlands for leaf monkeys from the Shanghai Zoo in China. Since Chinese zoos have a lack of successful breeding programs, they are more inclined to capture these cats for display purposes (p.1).

\section{Awareness, Enforcement, and Policy}

At both national and local levels, there is a lack of awareness about snow leopard conservation among policy-makers. These individuals have poor knowledge of conservation principles, and consequentially produce ineffective policies for conservation of snow leopards and their prey. No effective enforcement of protective measures are in place, as the required resources and basic equipment are not available to the staff and rangers who are, in general, underpaid (McCarthy \& Chapron, 2003, p. 32). Corruption among the enforcers is also problematic (p. 25). Because this species' mountainous range overlaps the borders of several Central Asian countries, there is a need for both transboundary cooperation and for enforcement of national and international trade laws (p. 32).

\section{Climate Change}

The Intergovernmental Panel on Climate Change (IPCC) predicts that the average annual temperature in South Asia and Tibet will increase by $3-4^{\circ} \mathrm{C}$ by $2080-2099$, and that the area will see increased precipitation (Forrest et al., 2010, p. 130). This may drive the forest further into the alpine region, thus decreasing the snow leopard's marginal preferred habitat even more (p. 130). In this study, Forrest et al. (2010) found that approximately $30 \%$ of snow leopard habitat will be vulnerable to change along the Himalayas (p. 132). Even if greenhouse gas emissions decrease by 2050, 10\% could still be lost. Habitat in Bhutan, Myanmar, and Nepal is likely to be pushed northward and populations in China and northern India may become completely isolated (p. 133). This change in environmental conditions may cause niches to overlap and, therefore, interspecific competition may increase (McCarthy et al. 2008, p. 1831). 


\section{Conservation Strategies and Actions}

CITES has legally protected the snow leopard across 12 range states (Jackson et al., 2008, para 23). Afghanistan also added them to their protected species list in 2009, thus banning all hunting and trade within the country (para. 7). Four countries-Mongolia, Pakistan, Nepal, and Russia-have existing national action plans, and India established Project Snow Leopard. India's plan, however, has not been adequately funded (para. 24). There are currently 109 protected areas $\left(276,123 \mathrm{~km}^{2}\right)$ known to have snow leopards inhabiting them, but some of these areas may not be ideal habitat, making the size misleading (McCarthy \& Chapron, 2003, p. 14). A study by Ale and Karky (2002), shows protected areas in Nepal fall outside snow leopard habitat, once more showing the lack of education about the species (p. 2).

SLSS recommends promoting livestock and grazing practices to reduce vulnerability to predation and more use of natural predator deterrents such as herding dogs (Jackson

et al., 2008, para. 22; Oli, Taylor, \& Rogers, 1994, p. 67). Ungulate trophy hunting programs need to be sustainable and monitored closely. The location, nature, and extent of these programs need to be addressed to reduce poaching and trade (McCarthy \& Chapron, 2003, p. 10). Additionally, there needs to be an increase in legal pressure (p. 10). Awareness needs to be made in China, specifically among medicine manufacturers, pharmacies, and customers. Wildlife conservation law enforcement should be tightened on trading routes, particularly in Songpan of Sichuan and Kashgar of Xinjiang. To decrease the snow leopard trade, there needs to be an increase in the exchange of and communication among wildlife management authorities in the snow leopard range countries (Wen, 2002, p. 4).

Integrated conservation strategies need to include climate change, especially the ecological and anthropogenic impacts (Forrest et al., 2010, p. 134). Actions can be immediately initiated: assessment of current anthropogenic threats, as they can worsen climate change; securing habitat that is less vulnerable to climate change for conservation; and programs to manage the land in snow leopard ranges more ecologically and appropriately (p. 134).

Country action planning is critical for conservation planning. This work would include analyzing the problem and choosing a proper scale, identifying key stakeholders and integrating them into planning achievable and appropriate actions, and monitoring results (McCarthy \& Chapron, 2003, p. 11). The likelihood of success can be improved by providing adequate education to the public, local officials of affected areas, and policymakers (Jackson et al., 2003, para. 15). The poverty in most of these areas ties these 
numerous issues together, and this connection shows the relationship between biodiversity conservation and the well-being of the local people (Ale \& Karky, 2002, p. 7).

To successfully carry out these conservation actions, these groups require improved knowledge on a wide range of issues. Studies of basic biology are needed. These studies would be large in number and varied in nature: snow leopard distribution, home range sizes, defining areas with high density, migration and movement routes, population size and fluctuations, size of protected areas, causes of habitat degradation and impacts, relationship with prey, ungulate and snow leopard diseases (type, area, and treatment), snow leopard social structure and behaviour, population genetics, food habits, relationship with other predators, and prey range and distribution (McCarthy \& Chapron, 2003, p. 48). The impact of human activities on this complex system are likewise essential for an understanding of the dynamics: wild ungulate and livestock interactions (grazing competition), livestock depredation rates and causes, snow leopard poaching levels, illegal trade, illegal ungulate hunting, monitoring techniques, analysis of existing policies and law, and human attitudes towards snow leopards (p. 53).

\section{Conclusion}

Of all the necessary requirements for a successful conservation project-improved knowledge, an understanding of snow leopard biology and their relationship with their prey, and legal matters_one component deserves special mention: the involvement of the local people in and around protected areas. Their cooperation and education is essential in conserving this species (Wang et al., 2006, p. 1). Improving their understanding and knowledge with education on the benefits of conservation can positively influence their attitude and involvement. These people will be directly impacted and will benefit by the policies made; they should be involved with decision-making (p. 1). Primary initial research needs to address basic status information on snow leopards, as this knowledge is lacking. The health of the environment can reflect the general wildlife conservation values in regions within the Central Asian mountains. Human populations and livestock populations are increasing the pressure on the fragile alpine ecosystems the snow leopard depends on. The future of this magnificent animal will ultimately depend on the actions and attitudes of both the local people in immediate contact with them and

support from local government officials (McCarthy \& Chapron, 2003, p.60). By increasing awareness and inspiring change, this species can be saved. 
* Author: Averil Jones is a fourth-year Bachelor of Science student, majoring in Biological Sciences, at MacEwan University. After completing her Bachelor, she plans on pursuing a graduate degree in Zoology or Conservation Biology, focussing on field research that will help us better understand how we can live in harmony with nature.

\section{References}

Ale, S.B. \& Karky, B.S. (2002). Observations on conservation of snow leopards in Nepal. International Snow Leopard Trust: Seattle.

Bhatnagar, Y.V., Mathur, V.B., \& McCarthy, T. (2002). A regional perspective for snow leopard conservation in the Indian Trans-Himalaya. International Snow Leopard Trust: Seattle.

Forrest, J.L., Wikramanayake, E., Shrestha, R., Areendran, G., Gyeltshen, K., Maheshwari, A., Mazumdar, S., Naidoo, R., Thapa, G.J., \& Thapa, K. (2010). Conservation and climate change: Assessing the vulnerability of snow leopard habitat to treeline shift in the Himalaya. Biological Conservation, 150, 129-135.

Jackson, R., Mallon, D., McCarthy, T., Chundaway, R.A. \& Habib, B. 2008. Panthera uncia. The IUCN Red List of Threatened Species. Version 2014.2.

$<$ www.iucnredlist.org>. Downloaded on 31 October 2014

Jackson, R. \& Wangchuk, R. (2001). Linking snow leopard conservation and peoplewildlife conflict resolution: grassroots measures to protect the endangered snow leopard from herder retribution. Endangered Species Update, 18 (4), 138-141.

Lovari, S., Ventimiglia, M., \& Minder, I. (2013). Food habits of two leopard species, competition, climate change and upper treeline: A way to the decrease of an endangered species?. Ethology Ecology \& Evolution, 25 (4), 305-318

McCarthy, T. M. \& Chapron, G. (2003). Snow Leopard Survival Strategy. International Snow Leopard Trust: Seattle.

McCarthy, K.P., Fuller, T.K., Ming, M., McCarthy, T.M., Waits, L., \& Jumabaev, K. (2008). Assessing estimators of snow leopard abundance. The Journal of Wildlife Management, 72, 1826-1833.

McCarthy, T.M., Fuller, T.K., \& Munkhtsog, B. (2005). Movements and activities of snow leopards in Southwestern Mongolia. Biological Conservation, 124, 527-537. 
Oli, M.K., Taylor, I.R., \& Rogers, M.E. (1994). Snow leopard Panthera uncia predation of livestock: an assessment of local perceptions in the Annapurna conservation area, Nepal. Biological Conservation, 68, 63-68.

Pires, Stephen, \& William Moreto. (2011). Preventing wildlife crimes: Solutions that can overcome the 'Tragedy of the commons'. European Journal on Criminal Policy \& Research, 17.2, 101-123.Snow Leopard Trust. (2015). About. Retrieved from: http://www.snowleopard.org. Accessed 29 June 2015.

Wang, S. W., Lassoie, J. P., \& Curtis, P. D. (2006). Farmer attitudes towards conservation in Jigme Singye Wangchuck National Park, Bhutan. Environmental Conservation, 33 (2), 148-156.

Wen, B. (2002). Illegal trade of snow leopards in China: an overview. Snow Leopard Survival Summit: Seattle 